\title{
Mitogenomic analysis of Montipora cactus and Anacropora matthai (cnidaria; scleractinia; acroporidae) indicates an unequal rate of mitochondrial evolution among Acroporidae corals
}

Received: 21 March 2004/ Accepted: 2 April 2005/Published online: 8 June 2005

(C) Springer-Verlag 2005

\begin{abstract}
The complete nucleotide sequence of the mitochondrial $(\mathrm{mt})$ genome was determined for specimens of the coral species Montipora cactus (Bernard 1897) and Anacropora matthai (Pillai 1973), representing two morphologically distinct genera of the family Acroporidae. These sequences were compared with the published $\mathrm{mt}$ genome sequence for the confamilial species, Acropora tenuis (Dana 1846). The size of the $\mathrm{mt}$ genome was $17,887 \mathrm{bp}$ and 17,888 bp for $M$. cactus and A. matthai. Gene content and organization was found to be very similar among the three Acroporidae mt genomes with a group I intron occurring in the NADH dehyrogenase 5 (nad5) gene. The intergenic regions were also similar in length among the three corals. The control region located between the small ribosomal RNA (ms) and the cytochrome oxidase 3 (cox3) gene was significantly smaller in $M$. cactus and $A$. matthai (both $627 \mathrm{bp}$ ) than in A. tenuis (1086 bp). Only one set of repeated sequences was identified at the $3^{\prime}$-end of the control regions in $M$. cactus and A. matthai. A lack of the abundant repetitive elements which have been reported for $A$. tenuis, accounts for the relatively short control regions in $M$. cactus and A. matthai. Pairwise distances and relative rate analyses of 13 protein coding genes, the group I intron and the largest intergenic region, igr 3 , revealed significant differences in the rate of molecular evolution of the $\mathrm{mt}$ genome among the three species, with an extremely slow rate being seen between Montipora and Anacropora. It is concluded that rapid mt
\end{abstract}

C.-C. Tseng · C. A. Chen $(\square)$

Research Centre for Biodiversity, Academia Sinica,

Nankang, Taipei 115, Taiwan

E-mail: cac@gate.sinica.edu.tw

Tel.: + 886-2-2789-9549

Fax: $+886-2-2785-8059$

C. C. Wallace

Museum of Tropical Queensland, Townsville, 4810, Queensland, Australia

C. A. Chen

Institute of Oceanography,

National Taiwan University, Taipei, Taiwan genome evolution is taking place in genus Acropora relative to the confamilial genera Montipora and Anacropora although all are within the relatively slow range thought to be typical of Anthozoa.

Keywords Mitochondrial genome $\cdot$ Acroporidae Slow evolution $\cdot$ Unequal rate of evolution

\section{Introduction}

Advances in nucleotide sequencing technology have enabled patterns of molecular evolution to be revealed based on genome-wide information. The mitochondrial (mt) genome has shown great potential for such studies. Animal mt genomes are usually intron-less, compact, closed circular DNAs, ranging in size from 14 to $40 \mathrm{~kb}$ (reviewed in Wolstenholme 1992). The gene content of animal mt genomes is usually conserved: 12 or 13 for proteins, one each for the small and large subunit ribosomal RNAs ( $m s$ and $r n l$ ), and 22 for transfer RNAs $(t R N A)$. In addition, one non-coding sequence (control region in vertebrates or AT-rich region in insects) is known to contain elements controlling the initiation of replication and transcription. Variations in the length of this region are responsible for size variations observed between mt genomes (Wolstenholme 1992). In addition, $\mathrm{mt}$ gene organization can differ substantially across phylogenetic levels.

This general view of animal $\mathrm{mt}$ genome organization has been modified since complete $\mathrm{mt}$ sequences were obtained from the Anthozoa (Bridge et al. 1992; Wolstenholme et al. 1992; Beagley et al. 1995, 1996, 1998; Beaton et al. 1998; Pont-Kingdon et al. 1998; van Oppen et al. 1999a, 2002). The $\mathrm{mt}$ genomes of a sea anemone, Metridium senile, and a reef-building coral, Acropora tenuis, each contain only two $t R N A \mathrm{~s}$, namely $t R N A^{\mathrm{fmet}}$ and $t R N A^{\text {trp }}$, and a group I intron, whereas only $t R N A^{\text {fmet }}$ is present in two octocorals, Renilla kolikeri and Sacrophyton glaucum (Beagley et al. 1996; van Oppen 
et al. 1999b, 2002). An open reading frame (ORF) encoding a putative mismatch repair protein is also present in these two octocorals (Pont-Kingdon et al. 1998).

Despite the unique features of anthozoan $\mathrm{mt}$ genomes, their rate of molecular evolution has been shown to be slow in relation to that exhibited by other animals (van Oppen et al. 1999a; Chen and Yu 2000; reviewed in Shearer et al. 2002). Results from phylogenetic analyses of Acropora mt cytochrome b (cytb) and $m s$ genes indicated that the rate of evolution in anthozoan mitochondrial genes is 10-20 times lower than the standard mitochondrial clock based on vertebrate sequences of 1$2 \%$ per million year (van Oppen et al. 1999a; Chen and $\mathrm{Yu}$ 2000). Shearer et al. (2002) reviewed DNA sequences of $\mathrm{mt}$ gene fragments commonly utilized in phylogenetic studies and concluded that slow evolution is probably a common feature not only in the anthozoans but also in other lower metazoans.

Corals in the family Acroporidae play a major role in reef coral diversity in the Indo-Pacific region (Wallace 1999; Veron 2000). The family includes four extant genera: Acropora, Anacropora, Astreopora, and Montipora. Two of these, Acropora and Montipora, are the most diverse genera in the scleractinian corals. There is thus considerable interest in establishing the evolutionary relationships among the genera in the family (Fukami et al. 1999; Wallace 1999; van Oppen et al. 2001). Ridley (1884) proposed that Anacropora was recently derived from Montipora, based on skeletal morphology and microstructure, while Veron (1995) suggested that Acropora might have evolved from an Anacropora-like ancestor. A morphological phylogeny of the entire family, including the extinct genus Dendracus indicated a basal clade of Montipora and Anacropora with Astreopora, Dendracus and finally two subgenera of Acropora as the terminal clade (Wallace 1999). Molecular phylogenetic analysis using cytb and ATP synthetase (atp6) genes also indicated a close relationship between Montipora and Anacropora (Fukami et al. 1999). In the present study, we determined the complete mt genomes of Montipora cactus and Anacropora matthai, using the long PCR technique, and compared these to the $\mathrm{mt}$ genome of A. tenuis (van Oppen et al. 2002) from Genbank. We then examined the molecular evolution of the three genera based on these three genomes.

\section{Materials and methods}

\section{Coral samples}

Spermwascollected froma M.cactuscolonyduring the 2002 spawning period at Chinwan Inner Bay, Penghu Islands (Hsieh et al. 2001). A tissue sample was collected from $A$. matthai (Museum of Tropical Queensland specimen G57868) at Walea Lighthouse, Bay of Tomini, Sulawesi, Indonesia, during the 1999 Tethyana expedition to Indonesiaby thesecond authorand preserved in $95 \%$ (v/w)ethanol.

DNA extraction, long PCR, cloning, and sequencing

Total DNA was extracted by the protocols described in Chen et al. (2002). Two fragments ( $9 \mathrm{~kb}$ each) covering the entire mt genomes of the A. matthai and M. cactus speci-

Table 1 Primers used in the long PCR and primer walking for DNA sequencing of the mt genomes of two Acroporidae corals

\begin{tabular}{|c|c|c|c|}
\hline Primer & $\begin{array}{l}\text { Oligonucleotide } \\
\text { sequence } \\
\left(5^{\prime} \rightarrow 3^{\prime}\right)\end{array}$ & Primer & $\begin{array}{l}\text { Oligonucleotide } \\
\text { sequence } \\
\left(5^{\prime} \rightarrow 3^{\prime}\right)\end{array}$ \\
\hline Monti12Slong- $\mathrm{B}^{\mathrm{a}}$ & $\begin{array}{l}\text { GACACGCTCCTCTAATTAA } \\
\text { AACAGTGAACAGCC }\end{array}$ & Monti12Slong- $\mathrm{A}^{\mathrm{a}}$ & $\begin{array}{l}\text { CAGCAGACGCGGTGAAACT } \\
\text { TAAGGGCTAGT }\end{array}$ \\
\hline Ana16SAint1 & ACGGATTGACTCGGATACT & Monti16SBint1 & TGTGTTAGTTTGCGACAGTA \\
\hline Mito16SAint4 & TCTATTGGGCTGATCATCA & Mito16SBint4 & AAATCAGAATATCGTCTC \\
\hline Mito16SAint5 & TACGACCAGCTTATGTCT & Mito16SBint5 & ATATAAACCTCTGGATGC \\
\hline Mito16SAint6 & CATGCATTATTGCGCAGA & Mito16SBint6 & GATGATCGTCTCCTAACA \\
\hline Mito16SAint7 & AAGACTCCTGTGGACGATGT & Mito16SBint7 & GAAGGCTAACGGTCTACT \\
\hline Mito16SAint8 & GTTGGTGGCGCTGTACTA & MO16BRint7 & GTTAACTCGAGGTCTTAGTA \\
\hline Mito16SAint9 & GGACATGGAGAGGCTGAT & Mito16SBint8 & CCCTCGTGAACACGTCTA \\
\hline Mito12SBint6 & AATCAACTTGAAGCAACT & Mito12SAint4 & TGGCTCCGGCTGTTGA \\
\hline AN12SBint7 & AAACAGATAGTCTCCTGGA & Mito12SAint5 & GTTTATTGGTGGGGCTCA \\
\hline AN12SBint8 & AАCCCACACAATAGAGCACA & Mito12SAint6 & ATGGTTCCGACATCGGAT \\
\hline Mito12SBint9 & AATTCCACTGCAACATCT & Mito12SAint7 & TATGGGTTTAACAATCGC \\
\hline
\end{tabular}

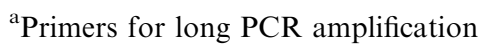


mens were amplified using the long PCR technique (Cheng et al. 1994). Four pairs of primers Monti16Slong-A, 5'GACTGCCAGGGGG AAACCTAGAGCAGACAC3', Monti12Slong-B, 5'-GACACGCTCCTCTAATT AAAACAGTGAACAGCC-3', and Monti16Slong-B, 5'GACAGTGAGACCCTCGT GACACCATTCATA-3', Monti12Slong-A, 5'-CAGCAGACGCGGTGAA ACTTAAGGGCTAGT-3' were designed on the basis of the partial sequences of $m s$ and $r n l$ genes available from the GenBank (Romano and Palumbi 1997; Chen and Yu 2000). Long PCRs were performed using the LA PCR Kit (Takara) under conditions recommended by the manufacturer. PCR was performed in a PC-9606 thermal sequencer (Corbett Research) using the following thermal cycle: 1 cycle at $94^{\circ} \mathrm{C}$ for $1 \mathrm{~min} .30$ cycles at $98^{\circ} \mathrm{C}(20 \mathrm{~s})$, $68^{\circ} \mathrm{C}(15 \mathrm{~min})$, and 1 cycle at $72^{\circ} \mathrm{C}$ for $10 \mathrm{~min}$. The PCR products were electrophoresed in a $0.6 \%$ agarose (FMC Bioproduct) gel in 0.5X TAE buffer to assess the yield. PCR products were cloned using the pGEM-T system (Promega) under conditions recommended by the manufacturer. Nucleotide sequences were determined for complementary strands of two clones from each sample using an ABI 377 Genetic Analyzer. Primers used in this study are listed in Table 1 . The sequences obtained were submitted to GenBank under the accession numbers AY 903926 and AY903295 for M. cactus and A. matthai.

Sequence analyses

The DNA sequences were assembled using the software program, DNASTAR 5.05 (Madison, WI). The DNA sequences were compared with the mitochondrial DNA (mtDNA) sequences of $A$. tenuis (van Oppen et al. 2002). Pairwise genetic distances (p-distance) of 13 proteincoding genes, group I intron, and igr3 were calculated using PAUP 4.0 b10 (Swofford 2002). Relative-rate test was performed using Tajima's relative-rate test (Tajima 1993) implemented in MEGA 2.1 (Kumar et al. 2001).

\section{Results and discussion}

Gene content and organization

The entire nucleotide sequences of the circular mtDNA molecules of $A$. matthai and $M$. cactus were $17,887 \mathrm{bp}$

Table 2 Length and position of all coding and non-coding regions in $M$. cactus and A. matthai mt genomes

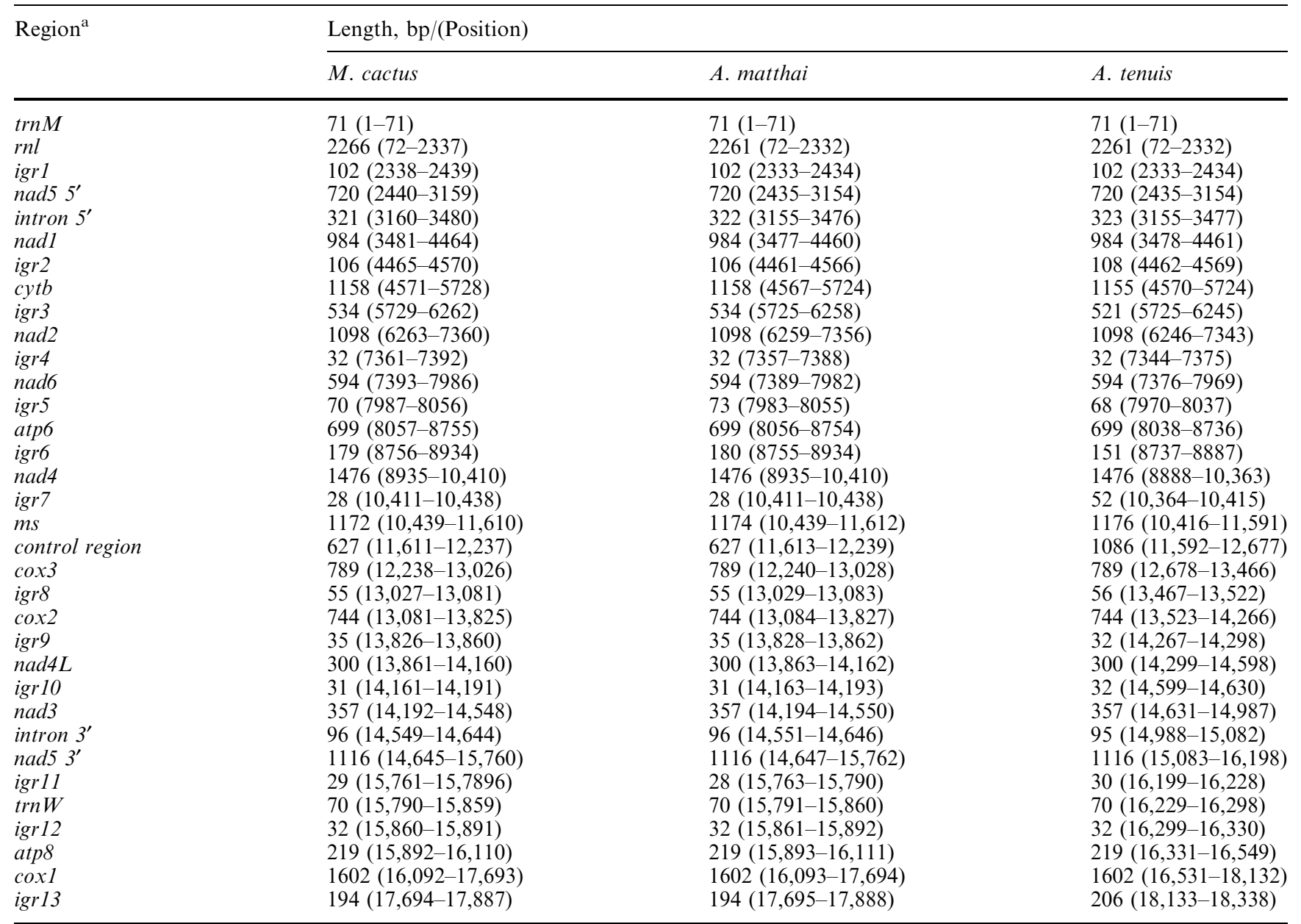

${ }^{\mathrm{a}}$ Abbreviations of $\mathrm{mt}$ genes and regions referred to be van Oppen et al. (2002) 
Table 3 Nucleotide content and length of the $\mathrm{mt}$ genomes in three Acroporidae corals as well as M. senile and S. glaucum

\begin{tabular}{|c|c|c|c|c|c|}
\hline Taxa & A $(\%)$ & $\mathrm{T}(\%)$ & $\mathrm{G}(\%)$ & $\mathrm{C}(\%)$ & Length (bp) \\
\hline M. cactus & 24.8 & 36.8 & 24.2 & 14.2 & 17,887 \\
\hline M. senile & 38.0 & 24.5 & 20.5 & 17.0 & 17,433 \\
\hline S. glaucum & 29.6 & 34.7 & 19.4 & 16.3 & 18,453 \\
\hline
\end{tabular}

and 17,888 bp in length (Table 2). These are compared with $M$. senile $(17,433 \mathrm{bp})$, A. tenuis (18,338 bp), Sarcophyton glaucum $(18,453 \mathrm{bp})$, and Renilla kolikeri (18,911 bp), (Table 3; Beagley et al. 1995, 1998; Beaton et al. 1998; van Oppen et al. 2002). Gene content and organization of the $\mathrm{mt}$ genomes of $M$. cactus and $A$. matthai (Fig. 1) are identical to those seen in A. tenuis with 13 protein genes, two rRNAs $(r n l, m s), 2$ tRNAs $(\operatorname{trn} M, \operatorname{trn} W)$, a putative control region, and a group I intron spanning within the nad5 gene in the genome (van Oppen et al. 2002). The complex repetitive elements occurring in the putative control region in A. tenuis (van Oppen et al. 2002) account for the size differences in the $\mathrm{mt}$ genomes among the three Acroporidae.

Nucleotide composition and codon usage

The nucleotide composition was $61.6 \% \mathrm{~A}+\mathrm{T}$ in the $\mathrm{mt}$ genome of both $M$. cactus and A. matthai. This is similar to the $\mathrm{A}+\mathrm{T} \%$ reported for $A$. tenuis, M. senile, $R$. kolikeri, and $S$. glaucum (Table 3) but lower than that in ther invertebrates (reviewed in Wolstenholme 1992). As

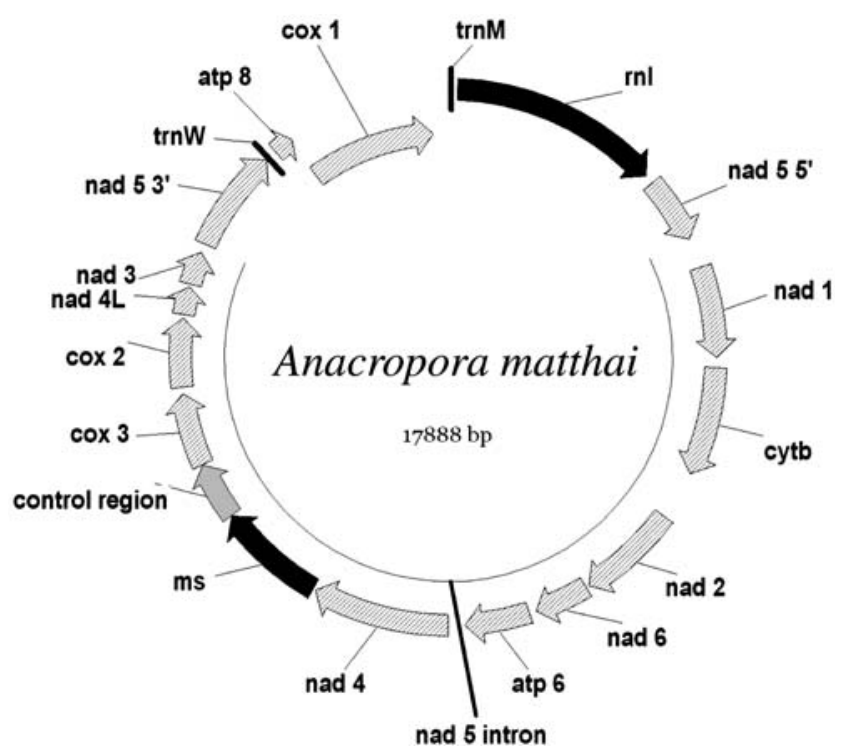

Fig. 1 Gene map of the A. matthai mt genome. The abbreviations of $\mathrm{mt}$ genes and regions referred to by van Oppen et al. (2002). The filled portions indicate the two ribosomal encoding genes. Proteincoding genes are indicated by the shaded portions. The large grey part represents the putative control region. Arrows indicate the direction of transcription. nad5 intron is also indicated shown in A. tenuis, the least used nucleotide is cytosine (14.2\% in both species) and the most used one is thymine $(36.7 \%$ in A. matthai and $36.8 \%$ in $M$. cactus). A similar nucleotide composition was reported for $M$. senile and two octocorals (Beagley et al. 1995, 1998; Beaton et al. 1998). In A. matthai and M. cactus, the start codons are GTG and ATG as in the mt genome of $A$. tenuis. The termination codons are TGA and TAA which also occur in the third position in other cnidarians. Two tRNAs, $\operatorname{trn} M$ and $\operatorname{trn} W$, are highly conserved in terms of size and composition in the mt genomes of all the three Acroporidae.

Intergenic spacers, putative control region, and nad5 group I intron

As documented in other published cnidarian $\mathrm{mt}$ genomes, the genes in the $\mathrm{mt}$ genome of the two Acroporidae studied here are not as closely packed as seen in higher animals (Beagley et al. 1995, 1998; Beaton et al. 1998; van Oppen et al. 2002). Thirteen intergenic regions (igr) are identified among the junctions of protein-coding genes in the $\mathrm{mt}$ genomes of each species with lengths ranging from $28 \mathrm{bp}$ (igr7) to $534 \mathrm{bp}$ (igr3) (Table 1). Pairwise distance of igr3 (ranging from 1.12 to $8.87 \%$ ) showed significant matches of intergenic spacers to those of $A$. tenuis, which indicate that the igrs are conserved among the three Acroporidae corals (Table 4). No match was found either between any of the Acroporidae and $M$. senile, or between Acroporidae and octocorals (see also van Oppen et al. 2002).

The rns cox 3 intergenic spacer has been suggested to act as a control region for the $\mathrm{mt}$ genome of $A$. tenuis (van Oppen et al. 1999b, 2002). The A. tenuis mt control region has typical features commonly associated with control regions in the higher animals, including repetitive sequences, conserved sequences blocks (CSB), and secondary structure associated with the initiation of heavy-strand replication (Rand and Harrison 1989; Zhang et al. 1995; Lavrov et al. 2000; Chen et al. 2004). These complex repetitive elements also accounted for variation in length in phylogenetic comparisons among the Acropora species (van Oppen et al. 2001). In contrast, only two copies of a 22-bp repeated fragment (5'-TAAAAAAGTT TTGMTAATTG TG-3') were identified at the $3^{\prime}$-end of control region of the $\mathrm{mt}$ genome in A. matthai and M. cactus (Fig. 2). Lack of other repetitive elements probably accounted for the shorter putative control re- 
Fig. 2 Alignment of the mitochondrial putative control region in $A$. matthai (AN) and M. cactus (MC). Repeats are marked by boxes

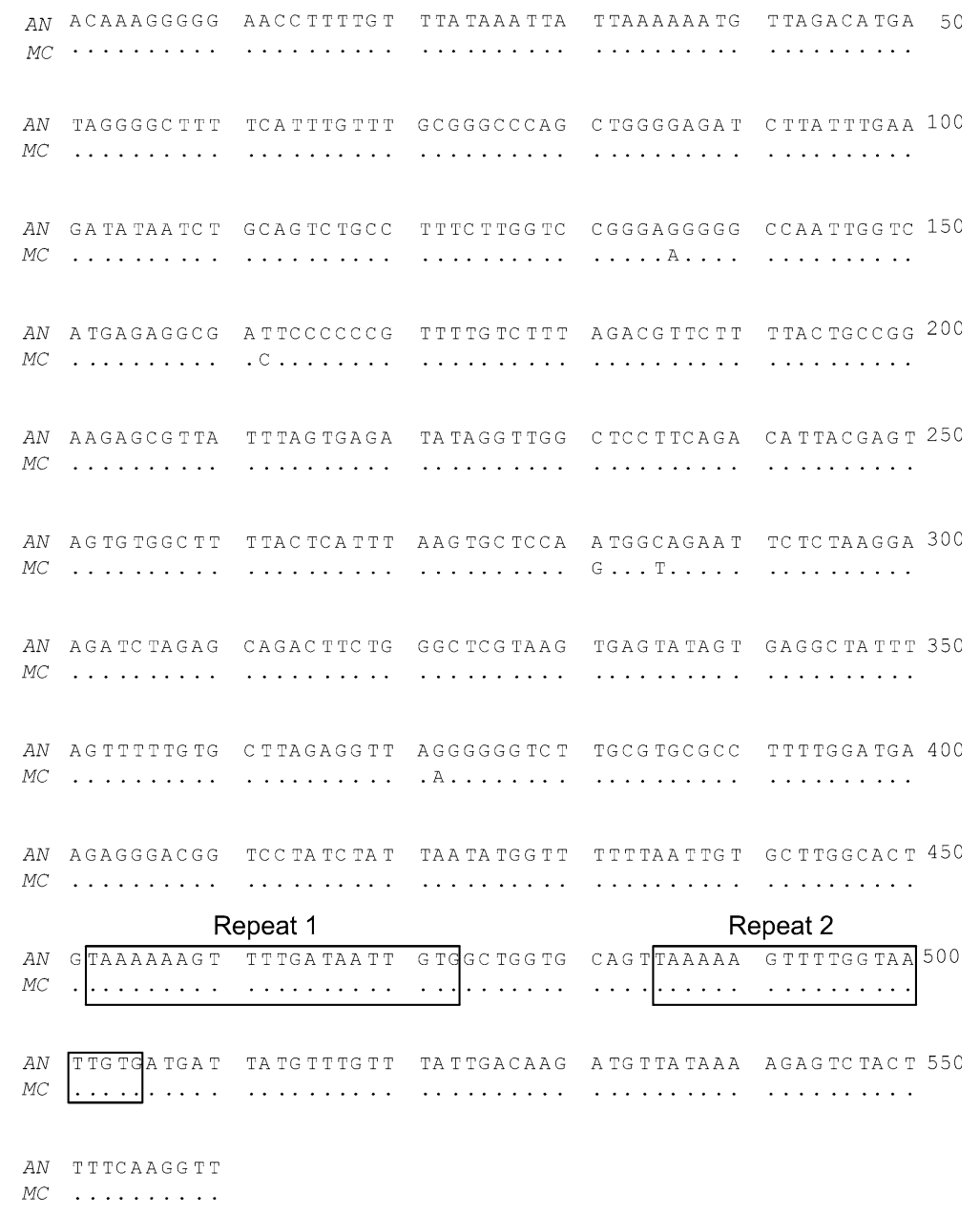

gion of A. matthai and M. cactus (627 bp) when compared with the same region of $A$. tenuis (1086 bp). Surprisingly, the core sequence of the 22-bp repeat ( $5^{\prime}$-AAAGTTTTGG- $3^{\prime}$ ) shows a complete match with the $A$. tenuis $\mathrm{mt}$ control region at positions 606 to 615 (data not shown), indicating a significant functional role for this region, although more comparative data are needed to test this proposal.

Group I intron reported for the mt genomes of $A$. tenuis and M. senile (Beagley et al. 1996; van Oppen et al. 1999b) was observed in the same position of the nad5 gene in both $A$. matthai and $M$. cactus. The size of group I intron is similar among the three Acroporidae (Table 1). Alignment of these group I introns indicated p-distances of 0.96 between Anacropora and Montipora, and of 6.01 between these two genera and Acropora (Table 4). Our data supports the hypothesis of van Oppen et al. (2002) that the nad5 group I intron was acquired by a common ancestor prior to divergence of the Scleractinia and Actinaria.

Pairwise distances and relative rate tests

Pairwise distances of the 13 protein-coding genes, nad5 group I intron, and the largest integenic spacer, igr3, demonstrated an extremely slow rate of evolution of the $\mathrm{mt}$ genomes between $A$. matthai and M. cactus (Table 4). These two species share three identical genes, atp8, nad3, and nad4L. The most divergent $\mathrm{mt}$ region between the two is $i g r 3$ with a p-distance of 1.12 . These rates are 3 to 8 times slower than those seen in A. tenuis. Tajima's relative-rate tests also strongly suggested that an unequal evolution rate occurred among the $\mathrm{mt}$ genomes of the three genera that has been studied (Table 4). From the p-distance comparisons and relative-rate tests, we conclude: first, the short p-distances in the 15-pair comparisons of $\mathrm{mt}$ regions indicate a close affinity between the genera Anacropora and Montipora. Molecular phylogenetic analyses of the three independent loci, including igr3, nuclear ribosomal internal transcribed spacer (ITS), and an intron spanning between exons 2 and 3 of the calmodulin gene (CaM-II), also indicated a close relationship between Montipora and Anacropora (Chang 2004). These results support both the morphological phylogeny of Wallace (1999) and the molecular phylogeny using $\mathrm{mt} c y t b$ and atp6 genes by Fukami et al. (1999). Secondly, the rate of $\mathrm{mt}$ genome evolution is unequal among the genera within the Acroporidae. This represents either an acceleration in Acropora or a slowing-down in Anacropora and Montipora after separation from their common ancestor. 
Table 4 Pairwise distances and Tajima's relative-rate tests ( $X^{2}$-test) of $13 \mathrm{mt}$ protein-coding genes, igr3, and the group I intron among three Acroporidae corals.

\begin{tabular}{|c|c|c|c|c|c|c|}
\hline Region & \multicolumn{3}{|l|}{$\mathrm{p}$-distance } & \multicolumn{3}{|l|}{$X^{2}$-test } \\
\hline atp 8 & 0 & 4.11 & 4.11 & $0^{\text {n.s. }}$ & $9 *$ & $9 *$ \\
\hline $\operatorname{cox} 1$ & 0.38 & 4.56 & 4.18 & $6^{\text {n.s. }}$ & $50.95 * *$ & $67 * *$ \\
\hline $\cos 2$ & 0.27 & 4.17 & 4.17 & $0^{\text {n.s. }}$ & $27.13 * *$ & $27.13 * *$ \\
\hline $\operatorname{cox} 3$ & 0.38 & 5.7 & 5.58 & $0.33^{\text {n.s. }}$ & $37.36^{* *}$ & $40.09 * *$ \\
\hline nad2 & 0.91 & 5.65 & 5.01 & $5.44^{\text {n.s. }}$ & $33.2 * *$ & $50.07 * *$ \\
\hline nad3 & 0 & 4.76 & 4.76 & $0^{\text {n.s. }}$ & $17 * *$ & $17 * *$ \\
\hline nad4 & 0.41 & 3.79 & 3.79 & $0^{\text {n.s. }}$ & $44.64 * *$ & $44.64 * *$ \\
\hline $\operatorname{nad} 4 \mathrm{~L}$ & 0 & 3.33 & 3.33 & $0^{\text {n.s. }}$ & $10^{*}$ & $10^{*}$ \\
\hline nad5 & 0.5 & 4.64 & 4.46 & $1^{\text {n.s. }}$ & $65.67 * *$ & $71.43 * *$ \\
\hline nad6 & 0.51 & 4.71 & 4.88 & $0.33^{\text {n.s. }}$ & $24.14^{* *}$ & $21.55^{* *}$ \\
\hline
\end{tabular}

Abbreviations: AN, A. matthai; AT, A. tenuis; MC, M. cactus. n.s., not significant; * $p<0.05 ; * * p<0.001$

Studies conducted on Acropora suggest that there is a potential for cross-species introgression among species of this genus (Marquez et al. 2002a, b; van Oppen et al. 2001; Vollmer and Palumbi 2002), which should slow down rates of molecular evolution at species level rather than increasing them. However, phylogenetic analysis (neighbor-joining tree) of the Family Acroporidae using $c y t b$ gene showed a significantly shorter tree length of Montipora/Anacropora lineage $(0.00712 \pm 0.00383)$ than that of the Acropora lineage $(0.03258 \pm 0.00712)$ (Fukami et al. 1999; Chen et al. unpublished data). In addition, analysis of nuclear ribosomal genes and spacers suggested that highly heterogeneous rate of divergence is observed only in the lineage of Acropora, not in Montipora/Anacropora, among all the scleractinian corals available so far (Chen et al. 2004; Wei et al. unpublished data). These preliminary evidences based on the gene fragment analyses imply that the molecular evolutionary rate of Acropora genomes, both mitochondrial and nuclear, are accelerated after divergence from the common ancestor of Montipora, Anacropora, and Acropora.

\section{Conclusions}

Complete DNA sequences are presented for the mt genomes of $A$. matthai and $M$. cactus. Only one other complete scleractinian $\mathrm{mt}$ genome has been reported to date (A. tenuis, van Oppen et al. 2002). We found that gene content, organization, features of intergenic spacers, and a group I intron were conserved among these three $\mathrm{mt}$ genomes of the family Acroporidae. However, the putative control regions in A. matthai and M. cactus were significantly shorter than that reported for $A$. tenuis (van Oppen et al. 2002) and this was attributed to the presence of a significantly smaller number of distinct repetitive elements in those two species. A highly conserved short fragment identified at the 3 '-end repeats of A. matthai and $M$. cactus $\mathrm{mt}$ control region was homologous that in A. tenuis, implying a functional role for this region. From p-distances and relative-rate tests, we concluded that more rapid mt evolution may be taking place within the genus Acropora than in Montipora and Anacropora, although all accord with the slower than usual rate of evolution proposed to be a general characteristic of the anthozoan mt genome (van Oppen et al. 1999a; Shearer et al. 2002). Further sequencing of species in these genera, as well as in Astreopora, is required to test this hypothesis.

Acknowledgements The authors wish to thank Jackie Wolstenholme for sample collection during the 1999 Tethyana expedition, and the staffs of the Penghu Aquarium for logistic support during coral spawning trips in 2002. Many thanks to Chang-Feng Dai, Jackie Wolstenholme, and Paul Muir, members of the Evolution and Ecology discussion group, and two anonymous reviewers for their constructive comments. This work was supported by grants from the Australian Research Council to C.C.W. and Institute of Zoology/Research Centre for Biodiversity, Academia Sinica (IZAS/RCBAS) to C.A.C. This is the Evolution and Ecology Group, IZAS/RCBAS Contribution no. 29.

\section{References}

Beagley CT, Macfarlane JL, Pont-Kingdon G, Okimoto R, Okada NA, Wolstenholme DR (1995) Mitochondrial genomes of Anthozoa (Cnidaria). In: Palmieri F, Papa S, Saccone C, Galadaleta N (eds) Progress in cell research - symposium on thirty years of progress in mitochondrial bioenergetics and molecular biology. Elsevier, Amsterdam, pp 149-153

Beagley CT, Okada NA,Wolstenholme DR (1996) Two mitochondrial group I introns in a metazoan, the sea anemone $M$. senile: one intron contains genes for subunits 1 and 3 of NADH dehydrogenase. Proc Natl Acad Sci, USA 93:5619-5623

Beagley CT, Okimoto R, Wolstenholme DR (1998) The mitochondrial genome of the sea anemone, $M$. senile (Cnidaria): introns, a paucity of tRNA genes, and a near-standard genetic code. Genetics 148:1091-1108 
Beaton MJ, Roger AJ, Cavalier-Smith T (1998) Sequence analysis of the mitochondrial genome of Sacrophyton glaucum: conserved gene order among octocorals. J Mol Evol 47:697-708

Bridge D, Cunningham CW, Schierwater B, DeSalle R, Buss L (1992) Class-level relationships in the phylum Cnidaria: evidence from mitochondrial genome structure. Proc Natl Acad Sci, USA 89:8750-8753

Chang CC (2004) Multi-loci approach to molecular phylogeny of reef-building corals, the genus Montipora (Scleractinia; Acroporidae). Msc thesis, Institute of Oceanography, National Taiwan University, p 51

Chen CA, Yu J-K (2000) Universal primers for amplification of mitochondrial small subunit ribosomal RNA-encoding gene in scleractinian corals. Mar Biotech 2:146-153

Chen CA, Wallace CC, Wolstenholme J (2002) Analysis of mitochondrial 12S RNA gene supports a two-clade hypothesis of the evolutionary history of scleractinian corals. Mol Phyl Evol 23:137-149

Chen CA, Chang CC, Wei NV, Chen CH, Lein YT, Lin HE, Dai CF, Wallace CC (2004) Secondary structure and phylogenetic utility of ribosomal internal transcribed spacer 2 (ITS2) in scleractinian corals. Zool Stud 43:759-771

Cheng S, Chang SY, Gravitt P, Respess R (1994) Long PCR. Nature 369:684-685

Fukami H, Omori M, Hatta M. (1999) Phylgenetic relationships in the coral family Acroporidae, reassessed by inference from mitochondrial genes. Zoo Sci 17:689-696

Hsieh HJ, Wei NV, Lu Y-I, Jeng M-S, Tsai W-S, Chen CA (2001) An unexpected high coral coverage in Chinwan Inner Bay, Pescadores: A potential site for Marine Protection Area. Coral Reefs 20:316-317

Kumar S, Tamura K, Jakobsen IB, Masatoshi N (2001) MEGA2: Molecular Evolutionary Genetics Analysis softwares. Arizona Sate University, Tempe

Lavrov DV, Boore JL, Brown WM (2000) The complete mitochondrial DNA sequence of the horseshoe crab Limulus polyphemus. Mol Biol Evol 17:813-824

Márquez LM, van Oppen MJH, Willis BL, Miller DJ (2002a) Sympatric populations of the highly cross-fertile coral species Acropora hyacinthus and $A$. cytherea are genetically distinct. Proc Royal Soc, London, Series B 269:1289-1294

Márquez LM, van Oppen MJH, Willis BL, Reyes A, Miller DJ (2002b) The highly cross-fertile coral species, Acropora hyacinthus and $A$. cytherea, constitute statistically distinguishable lineages. Mol Ecol 11:1339-1349

van Oppen MJH, Willis BL, Miller DJ (1999a) Atypically low rate of cytochrome $\mathrm{b}$ evolution in the scleractinian coral genus $\mathrm{Ac}$ ropora. Proc Roy Soc, London, Series 266:179-183 van Oppen MJH, Hislop NR, Hagerman PJ, Miller DJ (1999b) Gene content and organization in a segment of the mitochondrial genome of the scleractinian coral Acropora tenuis: major differences in gene order within the anthozoan subclass Zoantharia. Mol Biol Evol 16:1812-1815

van Oppen MJH, McDonald BJ, Willis BL, Miller DJ (2001) The evolution history of the coral genus Acropora (Scleractinia, Cnidaria) base on a mitochondrial and a nuclear marker: reticulation, incomplete lineage sorting or morphological convergence? Mol Biol Evol 18:1315-1329

van Oppen MJH, Catmull J, McDonald BJ, Hislop NR, Hagerman PJ, Miller DJ (2002) The mitochondrial genome of Acropora tenuis (Cnidaria; Scleractinia) contains a large group I intron and a candidate control region. J Mol Evol 55:1-13

Pont-Kingdon G, Okimoto R, Macfarlane JL, Beagley CT, Watkin-Sims CD, Cavalier-Smith T, Clark-Walker DG, Wolstenholme DR (1998) Mitochondrial DNA of the coral Sacrophyton glaucum contains a gene for a homologue of bacterial MutS: a possible case of gene transfer from the nucleus to the mitochondrion. J Mol Evol 46:419-431

Rand DM, Harrison RG (1989) Molecular population genetics of mtDNA size variation in crickets. Genetics 121:551-569

Romano S, Palumbi S (1997) Molecular evolution of a portion of the mitochondrial $16 \mathrm{~S}$ ribosomal gene region in scleractinian corals. J Mol Evol 45:397-411

Shearer TL, van Oppen MJH, Romanos SL, Worheide G (2002) Slow mitochondrial DNA sequence evolution in the Anthozoa (Cnidaria). Mol Ecol 11:2475-2487

Swofford D (2002) Phylogenetic analysis using parsimony v. 4.0b10 Sinauer, Sunderland

Tajima F (1993) Simple methods for testing molecular clock hypothesis. Genetics 135:599-607

Veron JEN (1995) Corals in space and time, the biogeography and evolution of Scleractinia. UNSW, Sydney

Veron JEN (2000) Corals of the world. Australian Institute of Marine Science, Townsville

Veron JEN, Wallace CC (1986) Scleractinia of the eastern Australia-Family Acroporidae. Australian Institute of Marine Science, Townsville

Vollmer SV, Palumbi SR (2002) Hybridization and the evolution of reef coral diversity. Science 296:2023-2025

Wallace CC (1999) Staghorn corals of the world: A revision of the genus Acropora. CSIRO, Collingwood

Wolstenholme DR (1992) Animal mitochondrial DNA: structure and evolution. Int Rev Cytol 141:173-216

Zhang DX, Szymura JM, Hewitt GM (1995) Evolution and structure conservation of the control region of insect mitochondrial DNA. J Mol Evol 40:381-391 